\title{
Natural Polysaccharides: An Overview of their Role in the Development of Microparticles for Stomach Targeting
}

\author{
Seema S Rathore1, Geetha M $^{2, *}$, S Ramachandra Setty ${ }^{3}$ \\ ${ }^{1}$ Department of Pharmaceutics, Collage of Pharmaceutical Sciences, Dayanand Sagar University, Bengaluru, Karnataka, INDIA. \\ 2Department of Pharmaceutics, Government College of Pharmacy, Bengaluru, Karnataka, INDIA. \\ 3Department of Pharmacology, Government College of Pharmacy, Bengaluru, Karnataka, INDIA.
}

\begin{abstract}
Development of safe and efficacious gastro-retentive dosage forms for stomach specific drug delivery have profound importance in pharmaceutical industry. Different approaches used for gastro retention are discussed with a special focus on the floating drug delivery systems. Natural polymers have great demand in drug delivery as they encompass polymers with many functional groups, wide range of molecular weights, varying chemical composition, for the most part, low toxicity and biodegradability yet high stability. Most of these polymers have been approved by many regulatory bodies all over the globe for their usage as pharmaceutical excipients; hence, their adoptability in formulation and development is hassle free. Natural polysaccharides have been investigated for drug delivery as well as biomedical applications. This review provides an overview of different stomach specific natural polymers used or currently being used specially for controlled drug delivery and the advantages of microparticles for stomach specific drug delivery including their preparation methodologies etc. The review also emphasizes a brief summary of existing challenges associated
\end{abstract}

with microparticles as delivery system for targeting drugs in the stomach and alternative methods/solutions adopted to overcome the same down the years.

Key words: Natural polysaccharides, Stomach specific microparticles, Floating drug delivery system, Gastro-retention, Controlled release, Sustained release.

\section{Correspondence}

Dr. Geetha M,

Assistant Professor, Department of Pharmaceutics, Government College of Pharmacy, No.2, P. Kalinga Rao Road, Subbaiah Circle, Bengaluru-560027, Karnataka, INDIA.

Phone: +919901844877

Email: geetha.rohinimalavika@gmail.com;

ORCID: http://orcid.org/0000-0002-3729-5303

DOI: 10.5530/ijpi.2020.2.18

\section{INTRODUCTION}

Despite remarkable advancements in drug delivery systems, the oral route remains the most preferred route for the administration of drugs because of low-cost therapy, ease of administration and great patient compliance. Despite the success, oral controlled drug delivery has faced physiological adversities like acidic environment of stomach or basic environment of intestine, short gastric residence time (GRT) and unpredictable gastric emptying time. ${ }^{1}$ By extending the GRT, duration of release of drugs with improvement in bioavailability can be achieved for drugs with short half-life, less soluble at high $\mathrm{pH}$ environment with reduction in drug wastage. ${ }^{2,3}$ Moreover, it is apparent from the recent scientific and patent literature that an increased interest in novel oral control release (CR) dosage forms necessitates the exploration of different stratagems to retain drugs in the upper gastrointestinal tract (GIT) for a prolonged and predictable period of time. ${ }^{4}$

\section{DIFFERENT APPROACHES TO DEVELOP STOMACH SPECIFIC MICROPARTICULATE SYSTEMS}

Several techniques are currently being used to formulate successful stomach specific drug delivery systems such as high-density systems where the formulation is retained (sink) in bottom of the stomach, ${ }^{5}$ Polymer based low density floating drug delivery systems that show buoyancy in gastric fluids, ${ }^{6}$ stable super porous hydrogels in low $\mathrm{pH}$ environment, floating systems that remain buoyant with the aid of effervescent agents, ${ }^{7}$ raft forming agents in anti-reflux formulations, when react with gastric fluids form gel, ${ }^{8}$ expandable, un-foldable and swellable systems, bio-adhesive or mucoadhesive drug delivery systems, magnetic systems, ${ }^{9}$ and modified shape systems.

\section{CRITERIA FOR SELECTION OF DRUG CANDIDATE FOR STOMACH SPECIFIC MICROPARTICULATE SYSTEMS}

Drugs, having shorter half-life, ${ }^{10}$ low oral bio availability, ${ }^{11}$ low water solubility, ${ }^{12}$ dosing several times a day, undesirable fluctuations in gastric fluids ${ }^{13}$ active locally in the stomach, narrow absorption window in GIT, unstable in the intestinal or colonic environment, disturb normal colonic microbes, exhibit low solubility at high $\mathrm{pH}$ values ${ }^{14}$ are suitable candidates for formulation of gastro retentive microparticles.

\section{NATURAL POLYSACCHARIDES USED FOR THE PREPARATION OF MICROPARTICLES}

The drug release and better-floating properties of microparticles mainly depend on the type of polymer, surfactant and solvent used in the preparation. ${ }^{15}$ Various types of natural polymers have been reported for their role in formulation of stomach specific floating microparticles. Commonly used natural polymers are polysaccharides (Table 1). More than $90 \%$ of the carbohydrate mass in nature is in the form of polysaccharides. These are polymers of monosaccharides with high molecular weight. Polysaccharides are gel-forming agents as well as hydrocolloids (Table 1), when come in contact with gastric fluids form gel and they 


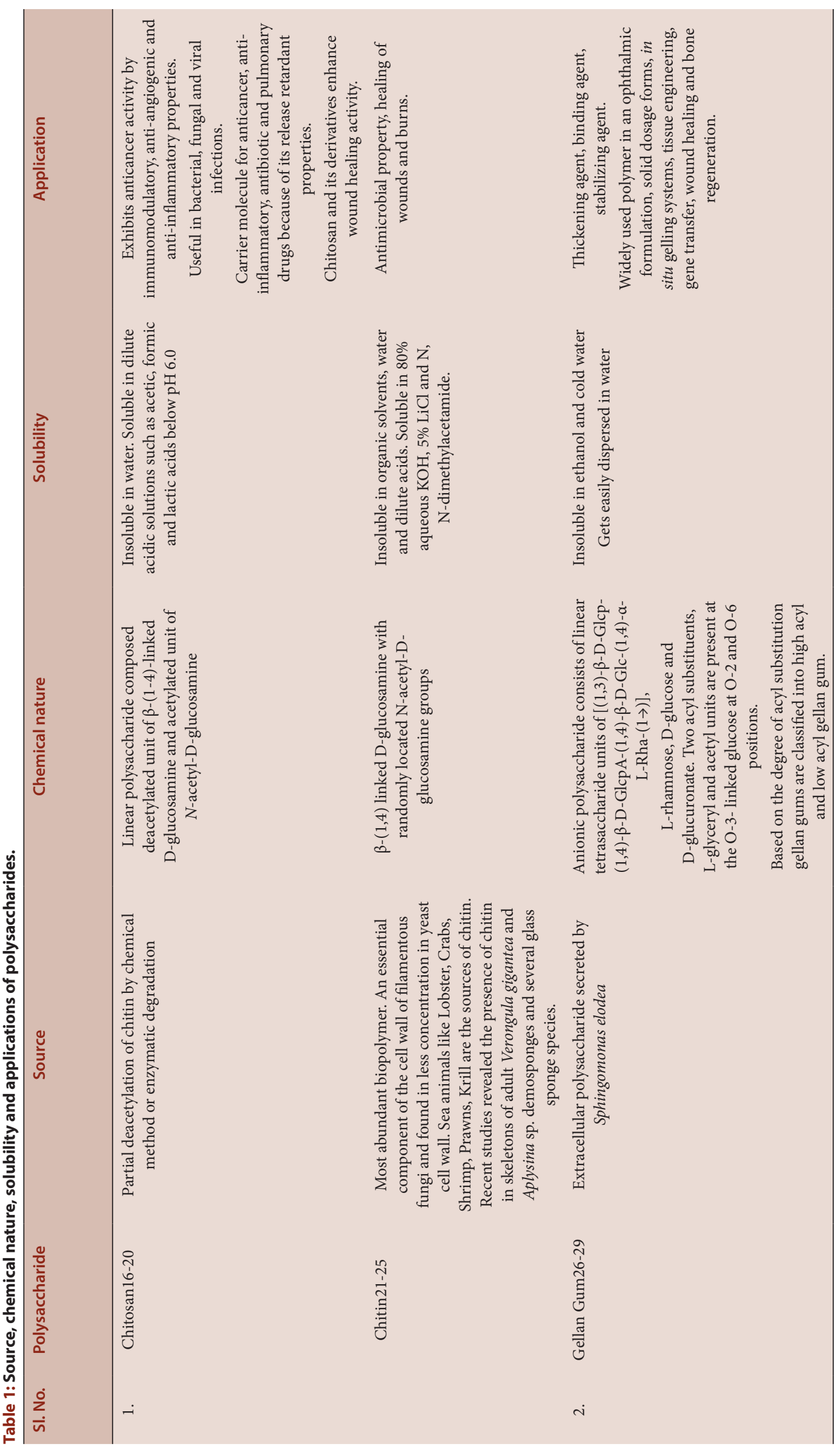




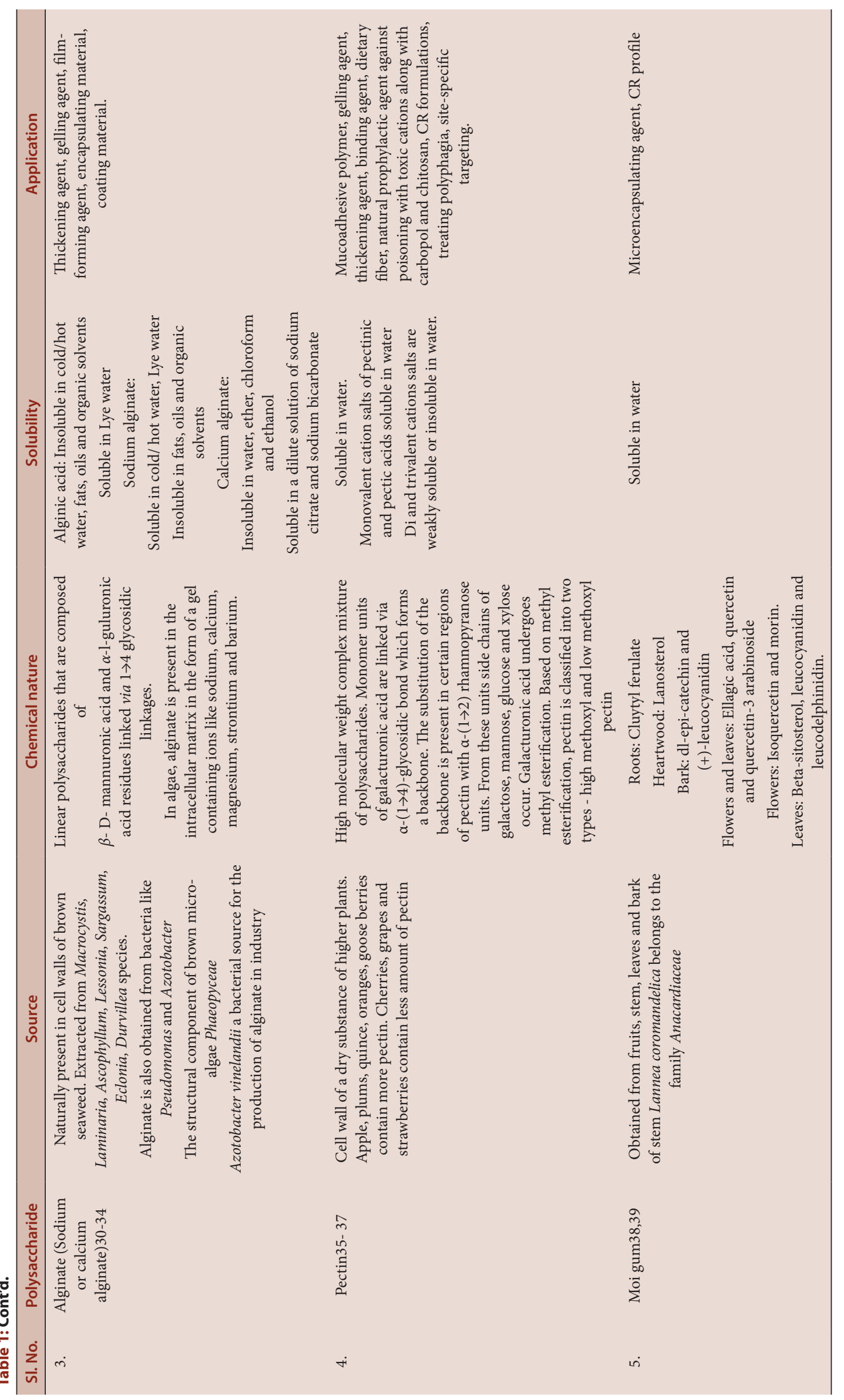




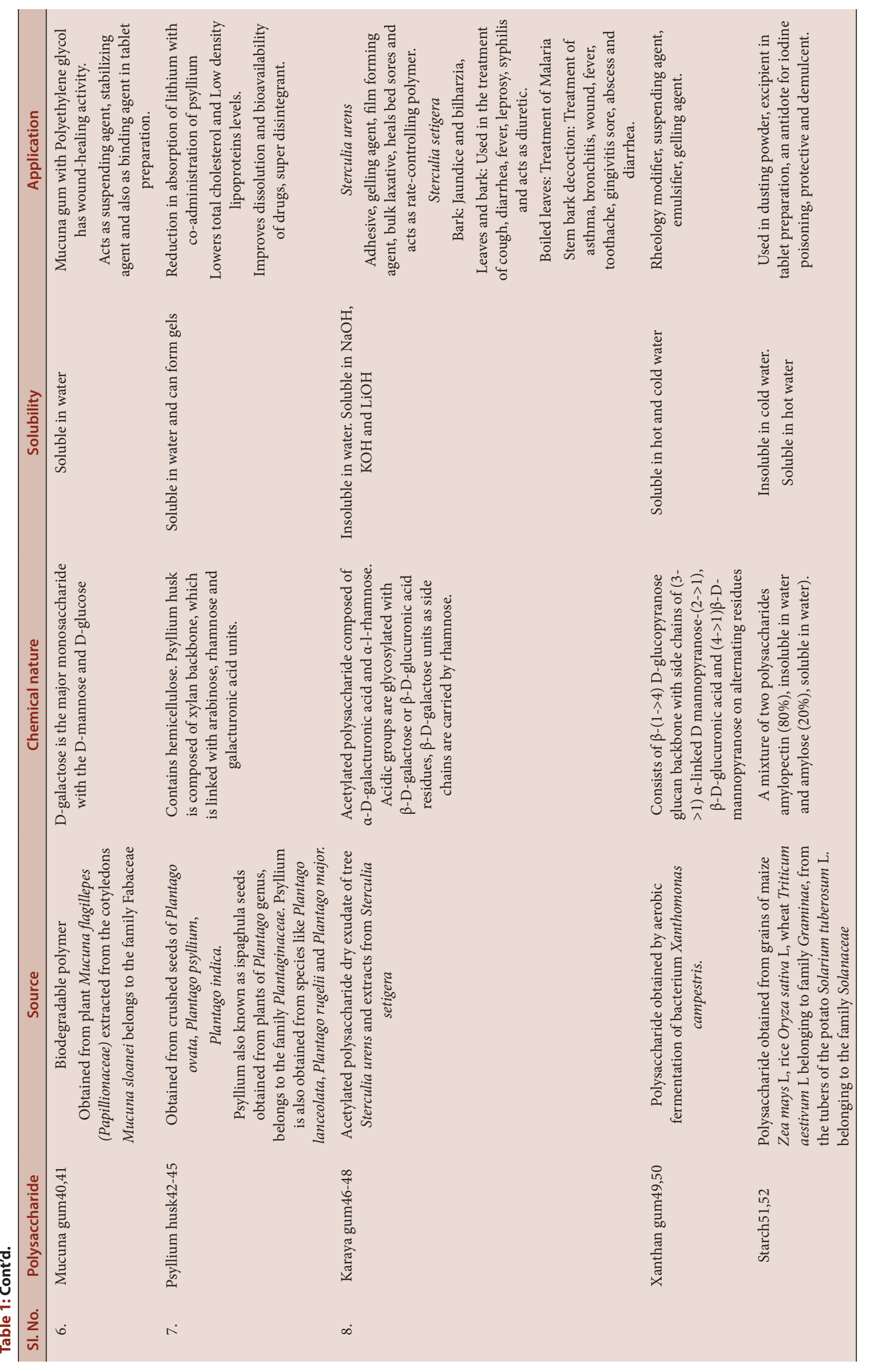


maintain relative integrity of the system by retaining the shape and also bulk density less than the gastric contents enabling buoyancy; in addition, help in maintaining desirable drug delivery properties.

\section{Chitosan}

Chitosan is a natural, non-toxic, biocompatible and biodegradable polymer obtained by alkaline deacetylation of chitin. ${ }^{53}$ It is soluble in acidic $\mathrm{pH}$ due to its cationic nature and possesses an antibacterial property. ${ }^{54}$ It forms gel beads with substances possessing multivalent counter-ions such as tripolyphosphate, alginates by ionotropic gelation method..$^{55}$ Drugs like 5- flurouracil, ${ }^{56}$ verapamil,,${ }^{57}$ metronidazole, ${ }^{58}$ atenolol, ${ }^{59}$ indomethacin ${ }^{60}$ are formulated as the chitosan based CR formulations and glutaraldehyde being the most commonly used cross-linking agent. ${ }^{61}$ It has been reported that celecoxib loaded microsphereswere prepared to increase its residence time in the stomach by emulsion cross-linking technique using chitosan as a polymer, glutaraldehyde and formal dehyde as cross-linking agents. The authors reported that microspheres cross-linked using glutaraldehyde exhibited delayed drug release than those cross-linked with formaldehyde; whereas the heat cross-linked microspheres showed fastest release. ${ }^{62}$ Similarly an attempt has been made to prepare and evaluate trimetazidin dihydrochloride loaded floating microspheres to increase the residence time in the stomach without coming in contact with the mucosa. The microspheres were prepared by the capillary extrusion technique using chitosan as polymer and sodium lauryl sulfate as cross-linking agent. The prepared microspheres demonstrated prolonged drug release and remained buoyant for more than $11 \mathrm{~h}$. The drug release rate was higher in case of microspheres prepared at a higher speed and decreased with an increase in the concentration of the polymer and cross-linking agent; vice-versa is reported in case of microspheres prepared at lower speed. The drug entrapment efficiency was found to increase with increase in polymer to drug ratio. ${ }^{63}$ In addition, there are reports on the development and characterization of stomach-specific drug delivery system to increase the efficacy of tetracycline against Helicobacter pylori infection in which chitosan was used as a polymer. The chitosan loaded microspheres were prepared by ionic cross-linking and by precipitation of chitosan with sodium sulphate. Two different methods were adopted to load the drug in microspheres. In the first method, tetracycline was mixed with chitosan solution before the simultaneous cross-linking and precipitation. In the second method, the drug was incubated with pre-formed microspheres for $48 \mathrm{~h}$. It was found that the drug-loaded by the method I was very less i.e., $8 \%$ and by method II it was found to be $69 \%{ }^{64}$

\section{Gellan gum}

Gellan gum has a characteristic property of cation induced gelation and it is widely used in CR formulations. ${ }^{65,66}$ An approach to develop and evaluate gellan gum beads containing cephalexin has been described in the literature. Beads were prepared by extruding the dispersion of cephalexin and gellan gum into a solution containing a mixture of calcium and zinc ions. Influence of variables such as $\mathrm{pH}$ of the counter ion solution and amount of cephalexin on response variables viz drug entrapment efficiency, release rate, particle size and morphology of beads were studied. The crystalline nature of the drug after its successful entrapment was studied by differential scanning calorimetry and indicated amorphous form of cephalexin loaded polymeric matrix. Fourier transform infrared spectroscopy reports suggested that there was no chemical interaction between drug, polymer and counterions. Light scattering results revealed spherical shaped beads. ${ }^{67}$

\section{Alginate (sodium or calcium alginate)}

Alginate is typically extracted from cell walls of brown algae (Phaeophyceae) of Laminaria and Ascophyllum species ${ }^{68}$ by treatment with aqueous alkali solution. ${ }^{69}$ After the filtration of extract, treatment of filtrate with sodium or calcium chloride results in formation of precipitated alginate. ${ }^{70}$ Sodium alginate is known for improving drug entrapment efficiency of floating microparticles. ${ }^{71}$ It has been reported that calcium alginate based floating beads of berberine were prepared by suspending octodecanol and berberine in sodium alginate solution. The usage of octodecanol in preparation of microspheres was intended to increase the sustained release properties and floating ability of beads. ${ }^{72}$ Likewise, alginate-based microspheres or microbeads have been formulated by coagulation ${ }^{73}$ and emulsification ${ }^{74,75}$ methods. In addition, development and evaluation of multi-unit gastro-retentive sustained release dosage form of a watersoluble drug, ranitidine hydrochloride is also mentioned in literature. The method ensured completely aqueous environment avoiding the use of organic solvent in the preparation for the effective treatment of peptic ulcer by releasing the drug in stomach for a prolonged period. Drug entrained micro-beads were prepared using sodium alginate as polymer by an emulsion gelation technique. Sodium alginate alone and sodium alginate along with pectin were used for the formulation. It was found that sodium alginate was not just enough to sustain the drug release in gastric $\mathrm{pH}$. Hence, an appropriate combination of alginate and pectin was used which could provide the sustained release drug release profile. ${ }^{76}$ Development of gastro-retentive sustained release alginate beads of diclofenac sodium has been reported as well. Beads were prepared by ionotropic gelation method by dispersing diclofenac sodium together with $\mathrm{CaCO}_{3}$ into a solution of sodium alginate. It was found that increased concentration of polymer has increased the drug entrapment efficiency. ${ }^{77}$ Similarly, a study was reported with respect to the formulation of floating dosage form of metformin hydrochloride using sodium alginate as a polymer. Conventional and oil entrapped alginate beads were prepared, former was prepared by ionotropic and later by emulsion gelation method. Different oils of standard pharmaceutical grade like light mineral oil, castor oil, vegetable oil (ground nut oil) and mentha oil were used to formulate and to study the effect of the same on the sustain release property of the formed beads. The oil entrapped calcium alginate gel beads showed better sustained release profile and specifically, liquid paraffin exhibited predominant sustained release action followed by ground nut oil $>$ castor oil $>$ menthol oil, when compared to conventional alginate beads. The results suggested that floating behavior of the beads ascribed to the density of oil used and the amount of oil required was found to be less with oils having less density. ${ }^{78}$ In a study, preparation and characterization of cefpodoxime proxetil floating beads using sodium alginate as a polymer were described. Floating beads were prepared by precipitation method using calcium carbonate as a gas generating agent. Increasing concentration of sodium alginate had decreased the bead size and increase in concentration of gas forming agent increased the bead size and floating ability. The \% Cumulative drug release results of in vitro dissolution study in glycine media for $12 \mathrm{~h}$, revealed that the higher concentration of the gas generating agent and lower concentration of sodium alginate provided maximum drug release due the formation of porous beads. ${ }^{79}$

\section{Pectin}

Pectin is one of the major plant cell wall components and probably the most complex macromolecule in nature as it is composed of 17 different monosaccharides containing more than 20 different linkages. ${ }^{80-82}$ High methoxyl, low methoxyl, amidated and non-amidated pectins (LMP) have been reported for their use in gastro retentive formulations. ${ }^{83}$ Rutin, ${ }^{83}$ Zinc pectinate beads, ${ }^{84}$ metronidazole,${ }^{85}$ metformin,${ }^{86}$ indomethacin ${ }^{87}$ 
were formulated in the form of microspheres using pectin and its derivatives. A reported method demonstrated the influence of method of preparation of pectin beads on the enhancement of drug loading using atenolol (cationic) and piroxicam (anionic) as model drugs. Pectin beads were prepared by dropping drug-containing pectin solution into calcium chloride solution. The droplets instantaneously turned into gelled spheres by ionotropic gelation. Variables like drug concentration, drying condition and calcium chloride concentration were considered for optimization of prepared beads. Infrared analysis reports suggested that the drug and pectin bound together with hydrogen bonds. In case of atenolol beads, the bead size dependent upon the drug concentration and drying method, whereas in piroxicam beads, the bead size was dependent only on drying condition. The encapsulation efficiency for both the drugs was found to depend on calcium chloride and drug concentration. Freeze dried beads of piroxicam showed increased dissolution of drug, whereas freeze dried atenolol beads had no effect. ${ }^{88}$ Also, as indicated in a study, conventional calcium pectinate gel beads and calcium pectinate gel beads containing edible oils like light mineral oil, olive oil, corn oil, soya bean oil, rice oil, sesame oil, peppermint oil and sun flower oil were prepared by homogenization technique by emulsion gelation method. The oil-entrapped calcium pectinate gel beads showed desirable floating property with enough oil being used when compared with that of conventional pectinate gel beads. Particle size of gel beads dependent upon the concentration of oil, as the oil volume increased the particle size also increased. The type and percentage of oil along with the relative density played an important role in controlling the floating behavior of oil-entrapped calcium pectinate gel beads. ${ }^{89}$ Furthermore, it was mentioned that effervescent floating beads containing ketorolac tromethamine was assessed for sustained release property in the stomach with reduction in dose and side effects. Floating beads were prepared by the extrusion congealing method using calcium carbonate as a gas-forming agent, alginate as polymer and hydroxyl propyl cellulose, sodium carboxy methyl cellulose, methyl cellulose and pectin as co-polymers. Beads prepared by using only alginate polymer showed low encapsulation efficiency and drug loading, usage of co-polymer along with alginate increased encapsulation efficiency and drug loading by forming two protective layers, which delayed the release of drug. The co-polymer concentration played a major role in the particle size of beads as well as swelling ability. As the concentration of co-polymer increased, the particle size and swelling behavior also increased. Results of analgesic effect studied by tail flick method from hot plate method revealed sustained effect of drug. The inference suggested that sodium alginate beads along with hydroxypropyl cellulose as copolymer showed better drug loading, floating and release profile..$^{0}$ Additionally, an investigation used six pectin derivatives with varying degree of methoxylation to formulate crystal violet encapsulated microspheres in combination with gellan gum. Based on the morphological characteristics of micropspheres, solubility, effect of calcium concentration and viscosity, amidated low methoxyl pectin was selected as a biopolymer. Hydrogel microspheres were prepared by extrusion of biopolymer solution through a $100 \mu \mathrm{m}$ diameter syringe coupled with a peristaltic pump. Pectin microspheres were stabilized with arabic gum and optimized according to the loading efficiency. Results obtained from optical microscopy showed spheroid shape of microspheres, with homogenous distribution of crystal violet. Crystal violet's use with biopolymer has shown reduction in viscosity due to molecular interaction between the mas confirmed by FTIR and Raman spectroscopic analysis. ${ }^{91}$

\section{Moi gum}

The gum is obtained from leaves, stems, fruits and most abundant in the bark of the Lannea coromandelica (Anacardiaceae). It is yellowish-white while fresh and upon drying becomes dark. Gum ducts are present in leaves, stems and fruits, most abundant in bark of the stem. It is used as microencapsulating agent and release rate controlling material. Moi gum-based microspheres are prepared by solvent evaporation technique and produced microspheres that have acceptable size, morphology and showed sustained release beyond 10 hours in comparison with guar gum but when used in 1:1 ratio showed better sustain release property. ${ }^{92,93}$

\section{Mucuna gum}

Mucuna gum is obtained from Mucuna flagillepes (Papillionaceae). It is composed of mainly D-galactose along with D-mannose and D-glucose. A study on suitability of mucuna gum microspheres of glibenclamide for oral delivery was demonstrated; the results showed that the formulation exhibited good in vitro release profile and it was also found that the microspheres had good swelling ability in distilled water, suggesting it is suitable for bioadhesive drug delivery system..$^{94}$

\section{Psyllium husk}

It is obtained from dried seed coats of Plantago ovata..$^{95}$ It contains a high proportion of hemicellulose composed of xylan backbone linked with arabinose, rhamnose and galacturonic acid units. ${ }^{96}$ It can form a gel with water and it is pale to medium buff-colored powder, with a weak characteristic odour. ${ }^{97,98}$ Psyllium husk has release retardant properties. It prolongs the retention time of dosage form in the stomach..$^{99}$

\section{Karaya or sterculia gum}

Karaya gum or Sterculia gum is exuded from the tree Sterculia urens, belongs to the family Sterculiaceae. ${ }^{100}$ It is naturally occurring polysaccharide constituted from L-rhamnose, $\mathrm{D}$-galactose and D-galacturonic acid. ${ }^{101}$ Sterculia gum has unique features such as high swelling, water retention capacity, high viscosity, inherent anti-microbial activity and abundant availability. ${ }^{[102]}$ It has been used as an emulsifier, stabilizer and thickening agent. It is a strongly acidic polysaccharide and has good stability in acidic preparations. ${ }^{103}$

The results obtained in an investigation suggested the therapeutic importance of sterculia gum and alginate polymers in controlling the release of pantoprazole from gastro-retentive drug delivery system prepared by ionotropic gelation method. ${ }^{104}$

\section{Xanthan gum}

Xanthan gum (XG) is a high molecular weight natural polysaccharide, due to its exceptional rheological properties acts as an effective stabilizer for water-based systems. XG is produced from a bacterium Xanthomonas campestris by fermentation process. It is a heteropolysaccharide with a primary structure consisting of repeated pentasaccharide units formed by two glucose units, two mannose units and one glucuronic acid units. ${ }^{105,106} \mathrm{XG}$ is also been used as an effective excipient for sustainedrelease formulations. ${ }^{107}$ Preparation of floating microspheres with microballoons inside using Theophylline as a model drug, XG and gelatin as polymers is been reported in a recent study. Microspheres were prepared by water in oil emulsification method varying the ratio of polymers. It was found that $\%$ yield, in vitro drug release rate and drug entrapment efficiency reduced with increasing gelatin content. ${ }^{108}$

\section{Starch}

Starch is the most commonly used polymer, obtained from jackfruit seeds; these seeds contain a high content of carbohydrate and protein. ${ }^{109}$ The major components of starch are two polysaccharides amylose and amylopectin. Amylose is a predominantly linear polysaccharide consisting of $\alpha-1,4$ linked D-glucopyranosyl units. ${ }^{110}$ Carboxymethyl starch powder is also been reported for its use in formulation of microspheres. ${ }^{111} \mathrm{~A}$ study proposed an attempt to formulate and characterize starch microspheres 
Table 2: Overview of source, drug, polymer, type of release and uses.

\begin{tabular}{|c|c|c|c|c|}
\hline Source & Drug & Polymer & Type of release & Uses \\
\hline $\begin{array}{l}\text { Aoki H, Iwao Y, Mizoguchi M, } \\
\text { Noguchi S, Itai S, } 2015.113\end{array}$ & Clarithromycin & Lubriwax-101 & Sustained release & $\begin{array}{l}\text { Macrolide antibiotic used to treat } \\
\text { bacterial infections. }\end{array}$ \\
\hline $\begin{array}{l}\text { Hooda A, Nanda A, Jain M, } \\
\text { Kumar V, Rathee P, } 2012.114\end{array}$ & Ranitidine $\mathrm{HCl}$ & Chitosan & Controlled release & Histamine $\mathrm{H} 2$ receptor antagonist \\
\hline $\begin{array}{l}\text { Stops F, Fell JT, Collett JH, } \\
\text { Martini LG. } 2008.115\end{array}$ & Riboflavin & Sodium alginate & Controlled release & Vitamin B2 supplement \\
\hline El-Gibaly I, 2002.116 & Melatonin & Chitosan & Controlled release & $\begin{array}{c}\text { Treating various circadian rhythm } \\
\text { disorders. }\end{array}$ \\
\hline Ma N, et al. $2008 .{ }^{117}$ & Diltiazem $\mathrm{HCl}$ & Chitosan, Eudragit RS30D & $\begin{array}{l}\text { Controlled release } \\
\text { (diffusion) }\end{array}$ & $\begin{array}{c}\text { Treatment of angina pectoris and } \\
\text { hypertension. }\end{array}$ \\
\hline $\begin{array}{c}\text { Kumar KV, Choudary PS, } \\
\text { Ajaykumar B, 2013. }\end{array}$ & Domperidone & Pectin & Sustained release & Antiemetic \\
\hline $\begin{array}{l}\text { Prakash S, Bhandari A, Mishra } \\
\text { R, Sharma PK, 2015. }{ }^{119}\end{array}$ & Gliclazide & Gum acacia, Sodium alginate & $\begin{array}{l}\text { Sustained and prolonged } \\
\text { release }\end{array}$ & $\begin{array}{l}\text { Anti-diabetic for type II Diabetes } \\
\text { mellitus }\end{array}$ \\
\hline $\begin{array}{c}\text { Shailaja T, Ramachandra S, } \\
\text { Kishore C, Bhushan YS, Lakshmi } \\
\text { PK, } 2013.120\end{array}$ & Diltiazem & $\begin{array}{l}\text { Karaya gum, xanthan gum, guar gum, } \\
\text { carrageenan, sodium bicarbonate }\end{array}$ & Sustained release & $\begin{array}{l}\text { Calcium channel blocker used for } \\
\text { the management of angina pectoris }\end{array}$ \\
\hline $\begin{array}{l}\text { Mahmoud HA, Melake NA, El- } \\
\text { Semary MT, 2012.121 }\end{array}$ & Tetracycline & Chitosan & Controlled release & $\begin{array}{c}\text { Against Pseudomonas aeruginosa } \\
\text { bacteria }\end{array}$ \\
\hline $\begin{array}{l}\text { Pasparalis G, Bouropoulos N, } \\
2006.122\end{array}$ & Verapamil & $\begin{array}{l}\text { Calcium alginate, calcium alginate- } \\
\text { chitosan beads }\end{array}$ & $\begin{array}{l}\text { Controlled drug release } \\
\text { (diffusion and swelling } \\
\text { controlled) }\end{array}$ & Treatment of hypertension \\
\hline Fathy M, 2006.123 & Meloxicam & Calcium alginate & $\begin{array}{l}\text { Controlled release profile } \\
\text { dependent upon swelling } \\
\text { and erosion of beads }\end{array}$ & $\begin{array}{l}\text { Treatment of ulcer, COX-2 } \\
\text { inhibitor }\end{array}$ \\
\hline
\end{tabular}

loaded with specific growth factors and immobilization in scaffolds. The starch microspheres were prepared using an emulsion cross-linking technique using meclofenamic sodium as a model drug. The method produced spherical microspheres and the processing variables played a major role in controlling the particle size. The influence of ionic strength of the medium demonstrated that the drug release was strongly dependent on salt concentration, being possible to classify this system as ionic strength dependent. ${ }^{112}$ The below mentioned Table 2 gives a comprehensive overview of various drugs, polymers, type of release and uses along with the source.

\section{ADVANTAGES OF NATURAL POLYSACCHARIDES}

- $\quad$ The natural polymers are more superior to the synthetic polymers with respect to their highly organized macroscopic and molecular structure. ${ }^{124}$

- Low toxicity and excellent biodegradability. ${ }^{124}$

- Biocompatible and safe.

- Low cost.

- Environment-friendly.

- Better patient tolerance.

- Easily available. ${ }^{125}$

- Less immunogenicity

- Acts as carrier for drug delivery by complementing the property of drug and other excipients used. ${ }^{126}$

- Provides controlled drug release

- Capable of chemical modification

- Combination of 2 or more polymers tend to provide better results in case of sustain release formulations

\section{DISADVANTAGES OF NATURAL POLYSACCHARIDES}

- $\quad$ Most of the polymers do not undergo enzymatic degradation. ${ }^{127}$

- Sometimes the degradable polymers exhibit substantial dose dumping.

- A "burst effect" or high initial drug release soon after administration is typical. ${ }^{128}$

- Variable biocompatibility of polymers

- Due to impurities in the preparation extracts, it is difficult to reproduce some of the properties of polymer. ${ }^{129}$

\section{APPLICATIONS OF NATURAL POLYSACCHARIDES}

- $\quad$ Polysaccharides are generally employed in floating drug delivery systems to target the delivery of the drug to a specific region in the GIT. ${ }^{130}$

- Polysaccharide polymers are used to prepare the gas and gaseous precursor filled microparticles used for magnetic resonance imaging of the stomach. ${ }^{131}$

\section{ADVANTAGES OF STOMACH SPECIFIC DRUG DELIVERY SYSTEMS}

Enhanced GRT: Increased gastric residence can be achieved, when the density of the formulation is less than gastric contents in case of floating systems; muco adhesion because of bioadhesive property of the system; high density system due to its sinking property and formation of hydrated gel layer around the system by making it as superporous hydrogel, modified shape and expansion systems. 
Improved patient compliance: The chances of missing a dose with a shorter half-life are common in the case of a conventional dosage forms which leads to poor patient compliance. This poor patient compliance can be circumvented by developing an effective technique using controlled drug delivery systems.

Desired therapeutic concentration: Most of the drugs are absorbed from the stomach region, hence the therapeutic concentration of drug in the plasma can be increased by gastro-retention to obtain the desired therapeutic response.

Increased safety: Safety margin for high potency drugs can be increased in the body because the plasma level of drugs can be controlled. The drug administered is completely being utilized, by reducing the total amount of drug administered.

Site-specific delivery of drug: Slow delivery of drugs at a specific site in the stomach can increase the therapeutic efficacy with the minimal amount of drug, which leads to less drug wastage.

Economical: The health care cost is reduced because of improved therapy, shorter treatment period and reduced dosing frequency.

\section{DISADVANTAGES OF STOMACH SPECIFIC DRUG DELIVERY SYSTEMS}

- Drugs having solubility or stability issues in the stomach environment or gastric fluids are difficult to formulate as stomach specific drug delivery systems.

- $\quad$ Floating drug delivery systems require a high gastric fluid volume to float and show the desired activity.

- Drugs which cause gastric mucosal irritation cannot be formulated as stomach specific drug delivery systems because of poor patient convenience and compliance.

\section{CONCLUSION}

Natural polysaccharides are widely been used in drug delivery systems because of their advantages over synthetic polymers. These polymers are easily available in nature and they are extracted from plant and animal sources. The selection of polymer plays a major role in the development of particulate drug delivery systems. Polymers can be used either alone or in combination with other polymers to possess better properties. Polymers discussed above influence gastric retention and release profile of drugs. From the research perspective, natural polysaccharides in addition to have gained importance in gastro-retentive drug delivery are extensively being used in cell targeting, nasal drug delivery systems, colon targeting and gene therapy. These polymers seem to be non-reactive with most of the drugs and are highly compatible with other excipients; this makes them to be used more abundantly in the advancement of drug delivery technologies.

Hence forth, the future explorations in the area of stomach specific microparticulate drug delivery using natural polysaccharides subsume, personalized medication approach as patients experience variation in GRT of the formulation affected by physiological factors; use of magnetic and ion exchange resin systems to increase GRT of the drug in the stomach which are not being widely used; reduction of burst effect using smart polymers which has the ability to release the drug at appropriate time and specific site; use of molecular imprinted polymers due to their high stability in gastrointestinal condition; application of artificial intelligence and target fishing to identify the biological targets ensuring accuracy in formulation development. Despite the extensive use of these polymers in research, impose application lacunae in commercially viable drug delivery systems. Thus, above mentioned approaches can be made possible to increase their usage in industries for wide gamut of profits.

\section{ACKNOWLEDGEMENT}

The authors are indebted to Government College of Pharmacy, Bengaluru and College of Pharmaceutical Sciences, Dayanand Sagar University, Bengaluru for providing necessary support to carry out this literature survey.

\section{ABBREVIATIONS}

CR: Controlled release; GIT: Gastro intestinal tract; GRT: Gastric residence time; $\mathbf{X G}$ : Xanthan gum.

\section{REFERENCES}

1. Iannucelli V, Coppi G, Bernabei MT, Camerorni R. Air compartment multipleunit system for prolonged gastric residence. Part-I. Formulation study. Int J Pharm. 1998;174(1-2):47-54

2. Garg R, Gupta GD. Progress in controlled gastroretentive delivery systems. Trop J Pharm Res. 2008;7(3):1055-66.

3. Nayak AK, Maji R, Das B. Gastroretentive drug delivery systems: A review. Asian J Pharm Clin Res. 2010;3(1):2-10.

4. Vyas SP, Khar RK. Gastroretentive systems. Controlled drug Delivery. Vallabh Prakashan, Delhi, India. 2006;197-217.

5. Rouge N, Allemann E, Gex-Fabry M, Balant L, Cole ET, Buri P, et al. Comparative pharmacokinetic study of a floating multiple-unit capsule, a high density multiple unit capsule and an immediate-release tablet containing $25 \mathrm{mg}$ atenolol. Pharm Acta Helv. 1998;73(2):81-7.

6. Sato $Y$, Kawashima $Y$, Takeuchi $H$, Yamamoto $H$. In vitro and in vivo evaluation of riboflavin containing microballoons for floating controlled delivery system in healthy humans. Int J Pharm. 2004;275(1-2):97-107.

7. Krogel I, Bodmeier R. Floating or pulsatile drug delivery systems based on coated effervescent cores. Int J Pharm. 1999;187(2):175-84

8. Pawar AY, Jadhav KR, Nikam MN. A raft formin0g system: A novel approach for gastroretention. Int J Pure App Biosci. 2015;3(4):178-92.

9. Huang Y, Leobandung W, Foss A, Peppas NA. Molecular aspects of muco- and bioadhesion: Tethered structures and site-specific surfaces. J Control Release. 2000;65(1-2):63-71.

10. Patel JK, Patel RP, Amin AF, Patel MM. Formulation and Evaluation of Mucoadhesive Glipizide Microspheres. AAPS Pharm Sci Tech. 2005;6(1):E49- 55

11. Ansary J, Chaurasiya AK, Huq KMB. Formulation and evaluation of metformin $\mathrm{HCl}$ floating microspheres. Asian J Med Biol Res. 2016;1(3):396-405.

12. Kyada C, Ranch K, Shah D. Optimization of mucoadhesive microspheres of acyclovir by applying 32 full factorial design. J Drug Deliv Sci Technol. 2014;24(1):61-8.

13. Gladiziwa U, Klotz U. Pharmacokinetics and Pharmacodynamics of H2-receptor antagonists in patients with renal insufficiency. Clin Pharmacokinet. 1993;24(4):319-32.

14. Sarojini S, Manavalan R. An overview on various approaches to gastroretentive dosage forms. Int J Drug Dev Res. 2012;4(1):1-13.

15. Sato $Y$, Kawashima $Y$, Takeuchi $H$, Yamamoto $H$. Physicochemical properties to determine the buoyancy of hollow microspheres (microballoons) prepared by the emulsion solvent diffusion method. Eur J Pharm Sci. 2003;55(3):297-304.

16. Sudhakar YN, Selvakumar M, Bhat DK. Methods of preparation of Biopolymer electrolytes. Biopolymer Electrolytes. 2018;35-52.

17. Shirvan AR, Shakeri M, Bashari A. Recent advances in application of chitosan and its derivatives in functional finishing of textiles. The impact and prospects of Green chemistry for textile technology. Sawston, Cambridge, United Kingdom: Woodhead publishing. 2019;107-33.

18. Bose A, Wong TW. Oral colon cancer targeting by chitosan nanocomposites Applications of nanocomposite materials in drug delivery. Sawston, Cambridge, United Kingdom: Woodhead publishing. 2018;409-29.

19. Das B, Patra S. Chapter 1 - Antimicrobials: Meeting the Challenges of Antibiotic Resistance through Nanotechnology. Nanostructures for Antimicrobial Therapy Amsterdam, The Netherlands: Elsevier. 2017;1-22.

20. Rajalekshmy GP, Devi LL, Joseph J, Rekha MR. An overview on the potential biomedical application of polysaccharides. Functional Polysaccharides for Biomedical applications. Sawston, Cambridge, United Kingdom: Woodhead Publishing. 2019;33-94.

21. Ohno N. Yeast and Fungal Polysaccharides. Comprehensive Glycoscience From Chemistry to Systems Biology. Amsterdam, The Netherlands: Elsevier. 2007;559-77.

22. Usman A, Khalid S, Usman A, Hussain Z, Wang Y. Algal polysaccharides, nove application and outlook. Algae Based Polymers, Blends and Composites. Amsterdam, The Netherlands: Elsevier. 2017;115-53.

23. Verma D, Fortunati E. Biopolymer Processing and its Composites: An Introduction. Biomass, Biopolymer-Based Materials and Bioenergy. Sawston, 
Cambridge, United Kingdom: Woodhead Publishing. 2019;3-23.

24. Roy JC, Salaun F, Giraud S, Ferri A. Solubility of chitin: Solvents, solution behaviors and their related mechanisms, solubility of polysaccharides. Solubility of Polysaccharides. London, United Kingdom: Intech Open. 2017;109-27.

25. Felse PA, Panda T. Studies on applications of chitin and its dervatives. Bioprocess Eng. 1999;20:505-12.

26. Cui SW, Wu Y, Ding $\mathrm{H}$. The range of dietary fibre ingredients and a comparison of their technical functionality. Fiber-rich and Wholegrain Foods: Improving Quality. Sawston, Cambridge, United Kingdom: Woodhead Publishing 2013;96-119.

27. Compendium of Food Additive Specifications, Addendum 5. (FAO Food and Nutrition Paper-52 Add. 5). Rome. 1997;17-26.

28. World Health Organization. Food and Agriculture Organization of the United Nations.

29. Osmalek T, Froelich A, Tasarek S. Application of gellan gum in pharmacy and medicine. Int J Pharm.2014;466(1-2):328-40.

30. Nesic AR, Seslija SI. The influence of nanofillers on physical-chemical properties of polysaccharide-based film intended for food packaging. In: Grumezescu AM, editors. Nanotechnology in the Agri-Food Industry, 1st edition. Amsterdam, Netherlands: Elsevier. 2016;637-97.

31. Alba K, Kontogiorgos V. Seaweed polysaccharides (agar, alginate, carragenan) Encyclopedia of food chemistry. Amsterdam, Netherlands: Elsevier. 2019;240-50.

32. Qin Y, Jiang J, Zhao L, Zhang J, Wang F. Applications of alginate as a functional food ingredient. Biopolymers for Food Design. Cambridge: Academic Press. 2018;409-29.

33. Kimica- algin.com [Home page on internet]. Japan: Kimica. Available from https://kimica-algin.com/alginate/usage/

34. Chemical book.com [search engine of home page]. Available from: https:// www.chemicalbook.com/ProductChemicalPropertiesCB0485676_EN.htm

35. Srivastava P, Malviya R. Sources of pectin, extraction and its applications in pharmaceutical industry: An overview. Indian J Nat Prod Resour. 2011;2(1):10-18.

36. Mudgil D. The Interaction between Insoluble and Soluble Fiber. Dietary fiber for the prevention of cardiovascular disease. Los Angeles: Elsevier, Academic Press. 2017;35-59.

37. Sundar Raj AA, Rubila S, Jayabalan R, Ranganathan TV. A Review on Pectin: Chemistry due to General Properties of Pectin and its Pharmaceutical Uses. Open Access Sci Rep. 2012;1(12):1-4

38. Bhabani SN, Udaya KN, Patr KB, Prasant KR. Preparation and in vitro evaluation of lamivudine entrapped MOI microspheres for oral administration. Res J Pharm Technol. 2008;1:437-41.

39. Shankar NB, Kumar NU, Balakrishna PK, Kumar RP. Preparation and in vitro evaluation of lamivudine entrapped $\mathrm{MOI}$ microspheres for oral administration. Res J Pharm Technol. 2008;1 (4):437-41.

40. Bhaskar DA, Uttam KJ, Mahendrasingh A, Jayram CM, Bhanudas SR. Plant Exudates and Mucilage as Pharmaceutical Excipients. J Adv Phar Edu Res. 2013;3(4):387-402.

41. Onweluzo JC, Leelavathi K, Rao PH. Effect of Detarium microcarpum (Dm) and Mucuna flagellipes (Mf) gums on the quality of white bread. Plant Foods Hum Nutr. 1999;54(2):173-82

42. BeMiller JN, Whistler RL, Barkalow DG, Chen CC. Aloe, chia, flaxseed, okra, psyllium seed, quince seed and tamarind gums. Industrial Gums, Polysaccharides and Their Derivatives. San Diego, New York Boston; Academic Press. 1993;227- 56

43. Mehmood Z, Khan MS, Qais FA, Samreen Al. Herb and modern drug interactions: Efficacy, quality and safety aspects. New look to phytomedicine, London, United Kingdom: Academic Press. 2019;503-20.

44. Figueroa LE, Staffolo MD. Dietary Fiber (Psyllium, $\beta$-Glucan). Encyclopaedia of Food chemistry. Amsterdam, The Netherlands: Elsevier. 2019;61-9.

45. Khaliq R, Tita O, Antofie MM, Sava C. Industrial Applications of Psyllium: An Overview. Acta Univ Cibiniensis: Technical Series. 2015;67(1):209-14.

46. Setia A, Goyal S, Goyal N. Applications of gum karaya in drug delivery systems: A review on recent research. Pharm Lett. 2010;2(5):39-48,

47. Mariod AA, Mirghani MES, Hussein I. Sterculia setigera (Karaya gum Tree) A New Oil Source. Unconventional oil seeds and oil sources. London, United Kingdom: Academic Press. 2017:273-6.

48. Postulkova H, Chamradova I, Pavlinak D, Humpa O, Jancar J, Vojtova L. Study of effects and conditions on the solubility of natural polysaccharide gum karaya. Food Hydrocoll. 2017;67:148-56.

49. Tomlins P. Materials type for tissue scaffolds. Characterization and design of tissue scaffolds. Woodhead Publishing Series in Biomaterials. 2016;1-21.

50. Kulkarni VS, Shaw C. Use of polymers and thickeners in semisolid and liquid formulations. Essential Chemistry for Formulators of Semisolid and Liquid Dosages. London, United Kingdom: Academic Press. 2016;43-69.

51. Your article library.com [Starch- Source, preparation and uses]. Available from http://www.yourarticlelibrary.com/biology/carbohydrates/starch-sourcespreparation-and-uses/49554.

52. Guo MQ, Hu X, Wang C, Ai L. Polysaccharides: Structure and Solubility. Solubility of Polysaccharides. London, United Kingdom: Intech Open. 2017.
53. EIMeshad AN, El-Ashmoony M M, Floating furosemide gel beads: in vitro and in vivo evaluation. J Drug del Sci Tech. 2012;22(4):317-25.

54. Pahwa R., Bhagwan S., Kumar V., Kohli K. Role of natural polymers in the development of floating drug delivery systems. J Pharm Res. 2010;3(6):1312-8.

55. Dash M, Chiellini F, Ottenbrite RM, Chiellini E. Chitosan, A versatile semisynthetic polymer in biomedical applications. Prog Polym Sci. 2011;36(8):981-1014

56. Denkbas EB, Seyyal M, Piskin E. 5-Fluorouracil loaded chitosan microspheres for chemoembolization. J Microencapsul. 1998;16:741-9.

57. Yassin AEB, Alsara IA, Al-Mohizea AM. Chitosan beads as a new gastroretentive system of verapamil. Sci Pharm. 2006;74(4):175-88.

58. Murata Y, Sasaki N, Miyamoto E, Kawashima S. Use of floating alginate gel beads for stomach-specific drug delivery. Eur J Pharm Biopharm. 2000;50(2):221-6.

59. Lodhiya DJ, Mukheriee DJ, Dholkiya RB, Akbari BV, Siyani BG, Lathiya HN Gastroretentive system of atenolol using HPMC K15M. Int J Pharm Tech Res. 2009; 1(4):1616-20

60. Miyazaki S, Yamaguchi H, Yokouchi C, Takada M, Hou WM. Sustained-release and intragastric-floating granules of indomethacin using chitosan in rabbits. Chem Pharm Bul. 1988;36(10):4033-8.

61. Akbuga J, Durmaz G. Preparation and evaluation of cross-linked chitosan microspheres containing furosemide. Int J Pharm. 1994;111(3):217-22

62. Thakkar HP, Murthy RR. Effect of cross-linking agent on the characteristics of celecoxib loaded chitosan microspheres. Asian J Pharm. 2008;2(4):246-51.

63. EINahas HM, Hosny KM. Chitosan based floating microspheres of trimetazidin dihydrochloride; preparation and in vitro characterization. Indian J Pharm Sci. 2011;73(4):397-403

64. Hejazi R, Amiji M. Stomach-specific anti-H. pylori therapy. I: Preparation and characterization of tetracyline-loaded chitosan microspheres. Int J Pharm. 2002;235(1-2):87-94

65. Rozier A, Mazuel C, Grove J, Plazonnet B. Functionality testing of gellan gum, a polymeric excipient material for ophthalmic dosage forms. Int J Pharm. 1997;153(2):191-08

66. Sanzgiri YD, Maschi S, Crescenzi V, Callegaro L, Topp EM, Stella VJ. Gellanbased systems for ophthalmic sustained delivery of methyl prednisolone. $J$ Cont Rel. 1993;26(3):195-201.

67. Agnihotri SA, Jawalkar SS, Aminabhav TM. Controlled release of cephalexin through gellan gum beads: Effect of formulation parameters on entrapment efficiency, size and drug release. Eur J Pharm Biopharm. 2006;63(3):249-61.

68. Smidsrod O, Skjak-Bræk G. Alginate as immobilization matrix for cells. Trend Biotechnol. 1990;8(3):71-8.

69. Clark, DE.; Green, HC. Alginic acid and process of making same. US Patent. 2036922. 1936.

70. Rinaudo M. Main properties and current applications of some polysaccharides as biomaterials. Polym Int. 2007;57(3):397-430

71. Neeta MM, Satija S, Pandey P, Dahiya M. Relevance of ionotropic gelation technique in the development of floating multiparticulate drug delivery systems. Int J Adv Sci Res. 2016;1(4):54-9.

72. Zhang ZH, Sun YS, Pang H, Munyendo WL, Lv HX, Zhu SL. Preparation and evaluation of berberine alginate beads for stomach-specific delivery. Molecules. 2011;16(12):10347-56

73. Martinsen A, Skjak-Bræk G, Smidsrod O. Alginate as immobilization material: I Correlation between chemical and physical properties of alginate gel beads. Biotechnol Bioeng. 1989;33(1):79-89.

74. Lemoine D, Wauters F, Bouchend'Homme S, Preat V. Preparation and characterization of alginate microspheres containing a model antigen. Int J Pharm. 1998;176(1):9-19

75. Mofidi N, Aghai-Moghadam M, Sarbolouki MN. Mass preparation and characterization of alginate microspheres. Process Biochem. 2000;35(9):885-8.

76. Jaiswal D, Bhattacharya A, Yadav IK, Singh HP, Chandra D, Jain DA. Formulation and evaluation of oil entrapped floating alginate beads of ranitidine hydrochloride. Int J Pharmy Pharma Sci. 2009;1(1):129-40.

77. Rasel MAT, Hasan M. Formulation and Evaluation of floating Alginate beads of Diclofenac Sodium. Dhaka Univ J Pharm Sci. 2012;11(1):29-35.

78. Choudhury PK, Kar M. Preparation of Alginate gel beads containing Metformin Hydrochloride using emulsion- gelation method. Trop J Pharm Res. 2005;4(2):489-93.

79. Gadad AP, Patil MB, Naduvinamani SN, Mastiholimath VS, Dandagi PM, Kulkarni AR. Sodium Alginate Polymeric Floating Beads for the Delivery of Cefpodoxime Proxetil. Journal of Applied Polymer Science. 2009;114(3): 1921-6.

80. Mohnen D. Biosynthesis of Pectins and Galactomannas. Comprehensive natural products chemistry. Pregamon, Elsevier. 1999.

81. ONeill MA, Ishii T, Albersheim P, Darvill AG. Rhamnogalacturonan II: structure and function of a borate cross-linked cell wall pectic polysaccharide. Annu Rev Plant Biol. 2004;55:109-39

82. Ridley BL, ONeill MA, Mohnen D. Pectins: structure, biosynthesis and oligogalacturonide-related signaling. Phytochemistry. 2001;57(6):929-67. 
83. Jantrawuta P, Assifaoui A, Chambinb O. Influence of low methoxyl pectin gel textures and in vitro release of rutin from calcium pectinate beads. Carbohydr Polym. 2013;97(2):335-42.

84. Nagaich U, Chaudhary V, Gulati N, Nagaich J, Tonpay SD. Development and in vivo characterization of gastroretentive drug delivery system for the treatment of gastro esophageal reflux disease. Pharm Lett. 2014;6(3):92-101.

85. Pawar A, Gadhe A, Venkatachalam P, Sher P, Mahadik K. Effect of core and surface cross-linking on the entrapment of metronidazole in pectin beads. Acta pharm. 2008;58(1):78-85.

86. Banerjee P, Deb J, Roy A, Ghosh A, Chakraborty P. Fabrication and development of pectin microsphere of metformin hydrochloride. ISRN Pharm. 2012;1-7.

87. Lee CM, Kim DW, Lee HC, Lee KY. Pectin microspheres for oral colon delivery: preparation using spray drying method and in vitro release of indomethacin. Biotechnol Bioprocess Eng. 2004;9(3):191-5.

88. Aydin Z, Akbuga J. Preparation and evaluation of pectin beads. Int J Pharm. 1996;137(1):133-6.

89. Sriamornsak P, Thirawong N, Puttipipatkhachorn S. Morphology and Buoyancy of Oil-entrapped Calcium Pectinate Gel Beads. AAPS J. 2004;6(3):65-71.

90. Sayeh FAE, Ela AE, Hassan MA, El-Maraghy DA. Ketorolac tromethamine floating beads for oral application: Characterization and in vitro/in vivo evaluation. Saudi Pharm J. 2014;22(4):349-59.

91. Revuelta MV, Villalba ME, Navarro AS, Guida JA, Castro GR. Development of Crystal Violet encapsulation in pectin-Arabic gum gel microspheres. React Funct Polym. 2016;106:8-16.

92. Avachat AM, Dash RR, Shrotriya SN. Recent Investigations of Plant Based Natural Gums, Mucilages and Resins in Novel Drug Delivery Systems. Indian J Pharm Educ Res. 2011;45(1):86-99.

93. Choudhary PD, Pawar HA. Recently Investigated Natural Gums and Mucilages as Pharmaceutical Excipients: An Overview. J Pharm. 2014;1-10.

94. Anthony AA, Obichukwu JN. Mucuna gum microspheres for oral delivery of glibenclamide: In vitro evaluation. Acta Pharm. 2007;57(2):161-71.

95. Bruneton J. Pharmacognosy-Phytochemistry. Medicinal plants second edition. New York: Lavoisier Publishing Inc. 1999;90-121.

96. Belgamwar VS, Surana SJ. Floating bio adhesive drug delivery system using novel effervescent agents. Asian J Pharm. 2009;3(2):156-60.

97. Chavanpatil MD, Jain P, Chaudhari S, Shear R, Vavia PR. Novel sustained release, swellable and bioadhesive gastroretentive drug delivery system for ofloxacin. Int J Pharm. 2006;316(1):86-92.

98. Raval JA, Patel JK, Naihong L, Patel MM. Ranitidine hydrochloride floating matrix tablets on low density powder. Effect of formulation on processing parameters on drug release. Asian J Pharm Sci. 2007;2(4):130-42.

99. Kumar SA, Vivek D, Vandana A. Role of natural polymers used in floating drug delivery systems. J Pharm Sci Inno. 2012;1(3):11-5.

100. Leung AY. Karaya gum. Leung's Encyclopedia of Common Natural Ingredients used in Food, Drugs and Cosmetics. New York: J.Wiley and Sons. 1980;393-7.

101. Rao PS, Sharma RK. Studies on indian plant gums: Composition and graded hydrolysis of gum karaya (Sterculia urens Roxb).Proc Indian Acad Sci, 45A. $1957 ; 45(1): 24-9$

102. Gauthami S, Bhat VR. A Monograph on Gum Karaya. (National Institute of Nutrition, Indian Council of Medical Research, Hyderabad). 1992.

103. Sarathchandiran I, Suresh KP. Chracterization and standardization of gum karaya. Int J Biopharm. 2014;5(2):142-51.

104. Singh B, Chauhan D. Barium ions crosslinked Alginate and Sterculia gum-based gastroretentive floating drug delivery system for use in peptic ulcers. Int J Polym Mate. 2011;60(9):684-705.

105. Katzbauer B. Properties and applications of xanthan gum. Polym Degrad Stab. 1998;59(1-3):81-4

106. Garcia-Ochoa F, Santos VE, Casas JA, Gomez E. Xanthan gum: production, recovery and properties. Biotechnol Adv. 2000;18(7):549-79.

107. Talukdar MM, Kinget R. Swelling and drug release behaviour of xanthan gum matrix tablets. Int J Pharm. 1995;120(1):63-72.

108. Yang Z, Song B, Li Q, Fan H, Ouyang F. Preparation of microspheres with microballoons inside for floating drug-delivery systems. J Appl Polym Sci.
2004;94(1):197-202.

109. Vedha HBN, Praneetha T, Ramya DT Development of starch gelatin complex microspheresas sustained release delivery system. J Adv Pharm Technol Res. 2012;3(3):182-7.

110. Taggart P, Mitchell JR. Starch. Hand book of hydrocolloids. Sawston, Cambridge, United Kingdom: Woodhead Publishing. 2009;108-41.

111. Lemieux M, Gosselin P, Mateescu MA. Carboxymethyl starch mucoadhesive as gastroretentive dosage form. Int J Pharm. 2015;496(2):497-508.

112. Malafaya PB, Stappers F, Reis RL. Starch-based microspheres produced by emulsion crosslinking with a potential media dependent responsive behavior to be used as drug delivery carriers. J Mater Sci Mater Med. 2006;17(4):371-7.

113. Aoki H, Iwao Y, Mizoguchi M, Noguchi S, Itai S. Clarithromycin highly-loaded gastro-floating fine granules prepared by high-shear melt granulation can enhance the efficacy of Helicobacter pylori eradication. Eur J Pharm Biopharm. 2015;92:22-7

114. Hooda A, Nanda A, Jain M, Kumar V, Rathee P. Optimization and evaluation of gastroretentive ranitidine $\mathrm{HCl}$ microspheres by using design expert software. Int J Biol Macromolec. 2012;51(5):691-700.

115. Stops F, Fell JT, Collett JH, Martini LG. Floating dosage forms to prolong gastro-retention - the characterisation of calcium alginate beads. Int J Pharm. 2008;350(1):301-11.

116. El-Gibaly I. Development and in vitro evaluation of novel floating chitosan microcapsules for oral use: comparison with non-floating chitosan microspheres. Int J Pharm. 2002;249(1-2):7-21.

117. Ma N, Xu L, Wang Q, Zhang X, Zhang W, LiY, et al. Development and evaluation of new sustained-release floating microspheres. Int J Pharm. 2008;358(1):82-90

118. Kumar KV, Choudary PS, Ajaykumar B. Design and Evaluation of StomachSpecific Drug Delivery of Domperidone using Floating Pectin Beads. Int J Drug Dev Res. 2013;5(1):219-28.

119. Prakash S, Bhandari A, Mishra R, Sharma PK. Development and optimization of floating microspheres of gliclazide. Int J Pharm Sci Res. 2015;6(5):807-17.

120. Shailaja T, Ramachandra S, Kishore C, Bhushan YS, Lakshmi PK. Formulation and in-vitro evaluation of gastro retentive delivery of diltiazem hydrochloride using natural polymers. Int J Pharm Sci. 2013;3(1):129-35.

121. Melake NA, Mahmoud HA, El-Semary MT. Bactericidal activity of various antibiotics versus tetracycline-loaded chitosan microspheres against Pseudomonas aeruginosa biofilms. Afr J Microbiol. 2012;15:1-9.

122. Pasparakis G, Bouropoulos N. Swelling studies and in vitro release of verapamil from calcium alginate and calcium alginate-chitosan beads. Int J Pharm. 2006;323(1):34-42.

123. Fathy M. Ca-alginate beads loaded with meloxicam: Effect of alginate chemical composition on the properties of the beads and ulcerogenicity of the drug. $J$ Drug Deliv Sci Technol. 2006;16(3):183-9.

124. Singh A, Sharma PK, Malviya R. Release behavior of drugs from various natural gums and polymers. Polim Med. 2011;41(4):73-80.

125. Jani GK, Shah DP, Prajapati VD, Jain VC. Gums and mucilages: Versatile excipients for pharmaceutical formulations. Asian J Pharm Sci. 2009;4(5):309-23.

126. Priya VSV, Roy HK, Jyothi N, Prasanthi NL. Polymers in Drug Delivery Technology, Types of Polymers and Applications. Sch Acad J Pharm. 2016;5(7):305-8.

127. Coelho JF, et al. Drug delivery systems: Advanced technologies potentially applicable in personalized treatments. EPMA J. 2010;1(1):164-209.

128. Lodhi B, Parikh G, Gajare G, Dharashive A, Shinde S. Shrewd natural and synthetic biodegradable polymers for targeted sustain and controlled release formulation. J Inno Pharm Bio Sci. 2014;1(3):102-16.

129. Cohen S andrianov AK, Wheatley M, Allcock HR, Langer RS. Massachusetts Institute of Technology, The Penn State Research Foundation, assignee. Polymeric microparticles containing agents for imaging. United States patent US 5,562,099. 1996

130. Kaur R, Kaur S. Role of polymers in drug delivery. J Drug Deliv Thera. 2014;4(3):32-6

131. Unger EC. Imarx Therapeutics, Inc., assignee. Gas filled microspheres as magnetic resonance imaging contrast agents. United States patent US 6,315,981. 2001.

Article History: Submission Date : 08-02-2020; Revised Date : 16-03-2020; Acceptance Date : 14-04-2020.

Cite this article: Rathore SS, Geetha M, Setty SR. Natural Polysaccharides: An Overview of their Role in the Development of Microparticles for Stomach Targeting. Int. J. Pharm. Investigation. 2020;10(2):96-105. 